\title{
Can Ambient Scent Enhance the Nightlife Experience?
}

\author{
Hendrik N. J. Schifferstein • Katrin S. S. Talke • \\ Dirk-Jan Oudshoorn
}

Received: 24 August 2010 /Accepted: 13 April 2011 /Published online: 13 May 2011

(C) The Author(s) 2011. This article is published with open access at Springerlink.com

\begin{abstract}
Ever since smoking was prohibited in restaurants, bars, and clubs, undesirable smells that were previously masked by cigarette smoke became noticeable. This opens up opportunities to improve the dance club environment by introducing pleasant ambient scents that mask the unwanted odors and to allow competing clubs to differentiate themselves. A field study was conducted at three dance clubs using a $3 \times 3$ Latin square design with preand post-measurements of no-scent control conditions. The three scents tested were orange, seawater, and peppermint. These scents were shown to enhance dancing activity and to improve the evaluation of the evening, the evaluation of the music, and the mood of the visitors over no added scent. However, no significant differences were found between the three scents.
\end{abstract}

Keywords Smell $\cdot$ Club $\cdot$ Experience $\cdot$ Mood $\cdot$ Fragrance

H. N. J. Schifferstein $(\bowtie) \cdot$ D.-J. Oudshoorn

Department of Industrial Design, Delft University of Technology, Landbergstraat 15 ,

2628 CE Delft, The Netherlands

e-mail: h.n.j.schifferstein@tudelft.nl

K. S. S. Talke

Faculty of Business Administration,

Chair of Innovation and Entrepreneurship,

University of Hamburg,

Hamburg, Germany

D.-J. Oudshoorn

MoodScent,

Amsterdam, The Netherlands

\section{Introduction}

Since the smoking prohibition became effective in restaurants, bars, and clubs, customers have increasingly noted unpleasant smells, such as body odors and the smell of old beer that were masked before by cigarette smoke (e.g., Fragrance Foundation UK 2007). Although customers may appreciate the fact that the indoor environment is now healthier and that their clothes do not smell of smoke anymore when they come home, they may be bothered by the unpleasant smells when they are out, which can negatively affect the experience of their night out.

A possible solution to this problem is to install a fragrance machine that distributes a pleasant scent in order to mask the unwanted odors. Moreover, scents may improve the perceived quality of the environment (Mattila and Wirtz 2001; Spangenberg et al. 1996) or enhance the mood of the customers (e.g., Baron 1990; Cann and Ross 1989; Ehrlichman and Bastone 1992; Ehrlichman and Halpern 1988). Therefore, we performed a study to test the effectiveness of three ambient scents in improving the nightlife experience.

Mehrabian and Russell (1974) have proposed a stimulus-organism-response paradigm to study the effects of environmental stimuli on human behavior. According to their paradigm, environmental stimuli, such as smells, may affect people's affective states that in their turn affect approach or avoidance behavior. According to these authors, three dimensions underlie people's affective states: pleasure, arousal, and dominance (PAD). Schifferstein and Tanudjaja (2004) assessed the emotional associations on the three PAD scales for 14 fine fragrances. They found most significant differences between fragrances on the pleasure 
scale ( $27 \%$ of all comparisons), fewer differences on the arousal scale $(13 \%)$, and almost none on the dominance scale $(1 \%)$. These outcomes suggest that the pleasure and arousal dimensions will be the most relevant for evaluating the effects of ambient scents.

Indeed, the hedonic dimension (pleasant-unpleasant) is extremely important in the experience of odors (e.g., Engen 1982), and pleasant odors seem to be able to induce positive moods (e.g., Baron 1990). The presence of pleasant odors in comparison to no odor or unpleasant odors in stores or shopping malls can improve the store image and the intention to visit the store (Spangenberg et al. 1996). Furthermore, they increase product evaluations and buying intentions for products that are not (dis)liked extremely (Morrin and Ratneshwar 2000; Spangenberg et al. 1996). In addition, pleasant odors can increase the time spent in a store (Knasko 1989; Leenders et al. 1999; Nixdorf et al. 1992), the number of times products are examined (Spangenberg et al. 1996), and the amount of time taken to evaluate products (Knasko 1995; Morrin and Ratneshwar 2000), whereas they decrease the subjectively perceived amount of time spent in a store (Spangenberg et al. 1996). Furthermore, people are more likely to interact with other people (Zemke and Shoemaker 2007) and to help other people (Baron 1997). Although these effects do not necessarily imply that pleasant odors increase the number of items purchased or the total amount of money spent (Chebat et al. 2009; Knasko 1989), the changes in these indicators suggest that consumers are more interested in shopping when the shopping environment smells good.

According to Mattila and Wirtz (2001), the evaluation of the store environment improves if the diffused scent is congruent with the other elements of the store in terms of their arousing qualities. Hence, if the store owner would like to create an environment in which visitors can relax and is already playing relaxing background music, other scents would be appropriate than if he or she wanted to stimulate or activate the visitors. Scents that may have relaxing effects include lavender (Lehrner et al. 2005; Moss et al. 2003), chamomile (Moss et al. 2006), ylang-ylang (Moss et al. 2008), and orange (Lehrner et al. 2000; Lehrner et al. 2005). Scents that may have a stimulating effect include peppermint (Ho and Spence 2005; Moss et al. 2008; Warm, Dember and Parasuraman 1991; Warrenburg 2002) and rosemary (Moss et al. 2003).

A relaxing effect does not necessarily preclude an increase in alertness. For instance, Warrenburg (2002) asked panelists to indicate how much a fragrance had changed a given mood. These data showed that muguet and hyacinth were both described as having a relaxing and a stimulating effect. Apparently, participants can experience a heightened sense of calmness and at the same time an increase in awareness and energy (Warren and Warrenburg
1993). Analogously, nutmeg on the one hand reduced blood pressure in stressed individuals (reduced arousal, Warren and Warrenburg 1993; Warren et al 1987), but on the other hand, it increased performance in a vigilance task (increased alertness, Warm et al. 1991). Furthermore, when Chrea et al. (2009) asked participants to rate odorants on 36 affective terms, they found that the relaxing and stimulating effects of odors were strongly positively $(r=0.83)$, not negatively correlated.

Whether a scent is perceived as congruent or not is an important determinant of its acceptance and of the evaluation of its environment (e.g., Bone and Ellen 1999; Bosmans 2006; Schifferstein and Verlegh 1996). If a scent is dispersed in the environment and people do not expect this odor in that particular environment, they may feel uncomfortable, and they may leave the location because it smells bad. Therefore, it is important to make sure that an ambient scent is thematically congruent with its environment (Schifferstein and Blok 2002). For instance, diffusing the smell of sunscreen at an indoor beach party can be used to emphasize the beach theme. Spangenberg et al. (2005) found that Christmas scent led to favorable evaluations of a department store and its merchandise only when presented in combination with Christmas music. Furthermore, these authors showed that shoppers evaluated a clothing store and its merchandise more favorably in the presence of a gendercongruent ambient scent compared to an incongruent scent (Spangenberg et al. 2006). Analogously, Fiore et al. (2000) concluded that an appropriately fragranced display for sleepwear products generated the most positive effect on purchase intentions. In general, studies on the role of odorenvironment congruency indicate that an odor is likely to show the most positive effects if it fits in with the rest of the environment. Even if the advantages of better-fitting scents are not always remarkable, the detrimental effects of an incongruent odor tend to be substantial (Bone and Ellen 1999).

For the present study, three scents were selected that were perceived as pleasant and fitting with the nightclub environment. All these pleasant scents were expected to increase the revenue from drinks, increase the number of visitors, improve the mood of the visitors, and improve their evaluations of the club environment compared to a no-scent control condition. Possibly, improved visitors' mood might (partly) account for the effects found on the evaluation of the environment (e.g., Baron and Thomley 1994; Gulas and Bloch 1995). Therefore, mediation analyses (Baron and Kenny 1986) were performed in order to test whether mood works as a mediator for the positive effect of pleasant scents on the evaluation of the environment.

Because people tend to go out in clubs to have fun, amuse themselves, relax, and dance, it remains to be 
determined whether scents should relax or stimulate the public. The three selected scents differed with regard to their anticipated effect on the arousal dimension of affect. The stimulating smell (peppermint) was expected to enhance, the relaxing smell (orange) to attenuate, and the neutral smell (seawater) to have no effect on dancing activity in the clubs. An overview of the variables investigated is provided in Fig. 1.

\section{Method}

\section{Participants}

Participants consisted of visitors of three clubs, who were observed during their visit. A subset of visitors was invited to fill out a short questionnaire when they exited the club. In total, 849 questionnaires were administered. The number of questionnaires per night varied from 48 to 60. The percentage of men was 53.4, 42.9, and 53.4, and mean age was $20.2,20.6$, and 25.4 for locations 1,2 , and 3 , respectively. Respondents received no monetary compensation.

\section{Experimental Design}

The study used a $3 \times 3($ scent $\times$ location $\times$ week) Latin square design with pre- and post-measurements of the no-scent control condition. In each location, measurements were performed one night per week, always on the same day of the week. Scents were diffused only on target nights, not during the rest of the week. The study covered five nights per test location. On the first night, no scent was diffused as a control condition. In the consecutive 3 weeks, every week, a different scent was diffused on the target night by a fragrance machine. In the last week, no scent was used, resulting in a second control night (Table 1).

\section{Locations}

The study was conducted in three clubs in cities with a significant student population. For each club, tests were

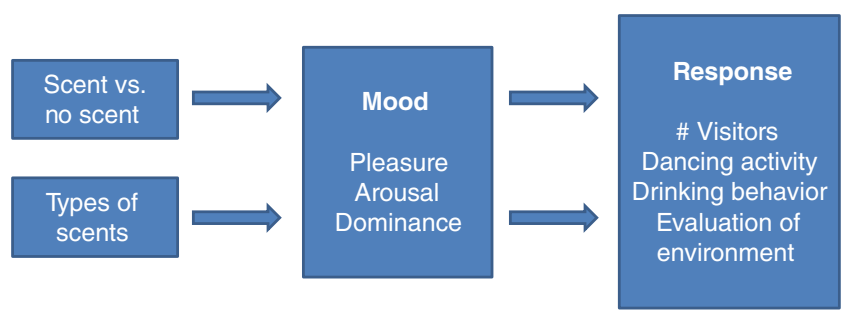

Fig. 1 Overview of the research conducted performed on the same night of the week, with the same music style played every week. The test night was a relatively busy night for the club, with $300-450$ people visiting each club. At locations 1 and 3, testing started at 0000 and lasted until 0400 hours. At location 2, testing started at 2300 hours because the club closed at 0300 . Tests were conducted in October and November 2008.

\section{Stimuli}

The three scents that were used for the experiments were orange (no. 102), seawater fresh and salty (no. 306), and peppermint (no. 007) provided by RetroScent, Rotterdam, The Netherlands. These scents were chosen on the basis of a prestudy performed among 67 visitors of four different clubs. In the prestudy, club visitors were presented with 10 scent sticks, each containing a different synthetic scent. Each scent was rated individually on a set of 7-point scales. The three experimental scents were selected because they differed considerably in odor character and nevertheless obtained relatively high and roughly comparable ratings on pleasantness $(M=4.5,4.3$, and 4.1 , respectively) and congruency with the club environment $(M=3.9,3.8$, and 3.4). In addition, according to our literature review, orange might have a relaxing effect (e.g., Lehrner et al. 2000; Lehrner et al. 2005), while peppermint was likely to have a stimulating effect (e.g., Ho and Spence 2005; Moss et al. 2008). No specific relaxing or stimulating effect was expected for the seawater fragrance.

The scents were provided in 200-ml cartridges and diffused using a RetroScent Smell \& Sell Classic system, which is suitable for rooms measuring up to $250 \mathrm{~m}^{2}$. This system uses a room temperature nebulizing system. The nebulizing pump is placed in the cartridge holding the perfume oil and creates a $100 \%$ aerosol. A fan mixes the aerosol with the surrounding air and transports the scent through the room. The machine has three adjustable settings: the speed of the nebulizing pump, the fan speed, and the number of minutes the machine is active per $15 \mathrm{~min}$.

For each club, the machine was adjusted up to a level at which the smell would be just noticeable throughout the space, without becoming evidently present. Fragrance distribution settings remained unchanged during the entire night. To accommodate differences in perceived intensity between fragrances, the maximum pump speed was set at $40 \%$ for peppermint, $50 \%$ for orange, and $60 \%$ for seawater at every location. The fan speed differed between locations and depended on the size of the space, the degree of air circulation, and the machine's distance from the ground. Because the dance floor at location 1 was large, the fan was set at maximum power. At location 2, the fan was set at $75 \%$ of maximum power because the dance floor was 
Table 1 The $3 \times 3$ Latin square design (weeks 2-4) with preand post-measurements of the no-scent control conditions

\begin{tabular}{llllll}
\hline & Week 1 & Week 2 & Week 3 & Week 4 & Week 5 \\
\hline Location 1 & No scent & Orange & Seawater & Peppermint & No scent \\
Location 2 & No scent & Seawater & Peppermint & Orange & No scent \\
Location 3 & No scent & Peppermint & Orange & Seawater & No scent \\
\hline
\end{tabular}

smaller and the fragrance machine was higher up from the floor. At location 3, the fan was set at $50 \%$ because it was located in front of another large ventilator. At all locations the machine was switched on for $7.5 \mathrm{~min}$ during each 15-min interval.

Procedure

Observational measurements were made at 30-min intervals during four consecutive hours in every location ( $t 1$ to $t 9$ ). At each measurement point, four to five pictures were taken from several fixed locations in the club in order to determine the number of visitors present. In addition, a 30 -s video was made. Subsequently, the percentage of people dancing was estimated by the experimenter, and the temperature inside the club was recorded using a weather station (accuracy $0.1^{\circ} \mathrm{C}$ ). Videos were used to cross-check the subjective estimates of the dancing activity.

During the last $2 \mathrm{~h}$ of measurement, exiting customers were asked whether they were willing to fill out a short questionnaire about how they liked the evening in the club. To avoid introducing bias and contaminating the potential subject pool on subsequent test occasions, no mention was made about the distribution of fragrances. Each night, between 48 and 60 questionnaires were filled out. The experimenter tried to distribute the questionnaires evenly over the $2 \mathrm{~h}$, so that approximately 15 questionnaires were filled out each $30 \mathrm{~min}$. Respondents evaluated the quality of the evening, the music, and the club on three 9-point scales (1=very bad, 9=very good). Subsequently, they reported their feelings from earlier in the night using a modified version of the Self-Assessment Manikin (SAM, Bradley and Lang 1994; Lang 1985). In our version of the SAM, each dimension of affective experience (pleasure, arousal, and dominance) was represented through five pictorial representations depicted above a 9-point rating scale with verbal end anchors (Fig. 2). Respondents were instructed to mark a category below a picture (or between pictures) that best matched their feelings that night. Finally, participants reported age and gender. After each test night, sales data were obtained in order to assess the customers' consumption behavior during the night.

\section{Data Processing and Analysis}

Sales data were used to calculate the total revenue, the revenue from beer, and the revenue from liquor on each night. To correct for differences in location size and visitors' drinking behavior, the mean revenue for each location in the two no-scent control weeks was set to 100 , and all revenues for a location were calculated relative to this number. For each type of data (total, beer, and liquor), we compared sales across nights (three experimental and two no-scent control conditions) by repeated measures analysis of variance (ANOVA) with condition as the only within-location variable.

The number of visitors, dancing activity, and temperature were measured nine times per evening. These data
Fig. 2 The adapted version of the three visual scales of the Self-Assessment Manikin used in the present study

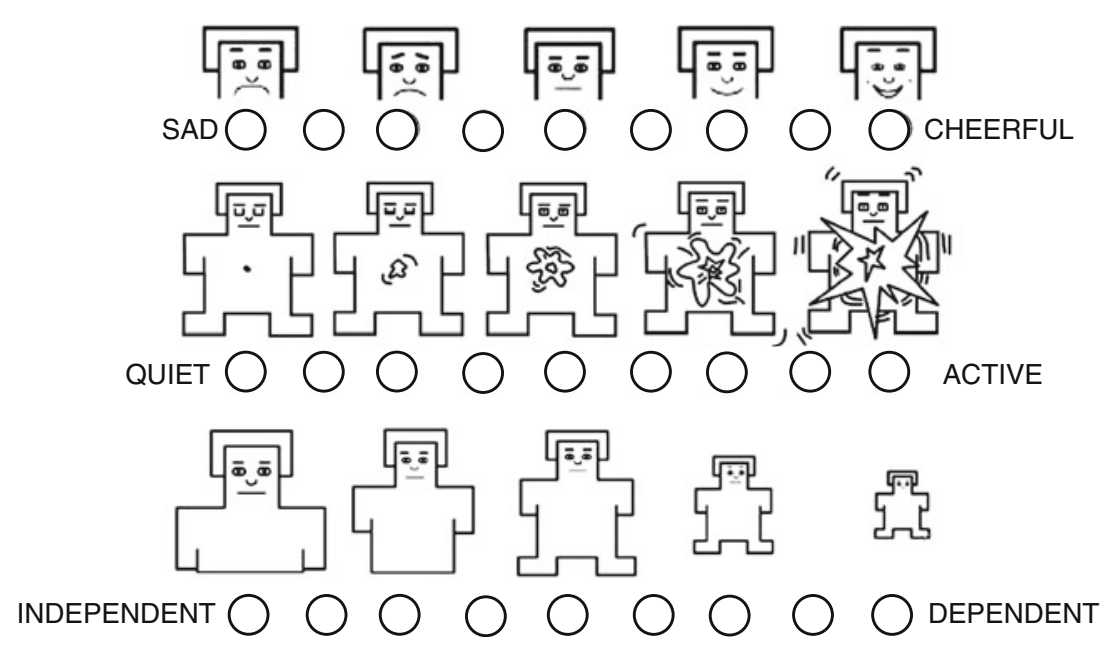


were analyzed by repeated measures ANOVA with condition (five levels) and time (nine levels) as within-location variables. In accordance with Stevens (2002), we corrected the degrees of freedom in all repeated measures ANOVAs with the Greenhouse-Geiser $\varepsilon$ if $\varepsilon<0.7$, and we averaged the $\varepsilon$ values from Greenhouse-Geiser and Huynh-Feldt when $\varepsilon>0.7$.

To investigate whether scents affected the dependent variables compared to the unscented control condition, we tested whether the mean of the three scented experimental conditions differed significantly from the mean of the two unscented control conditions in two-tailed paired $t$ tests. Differences between the three experimental conditions (orange, seawater, or peppermint) were investigated by two-tailed post hoc $t$ tests with Bonferroni adjustment.

For the analyses of self-report measures, we used a different type of model for statistical analyses because the individual respondent was now the unit of analysis instead of the location of the study. The between-participant factors in these univariate ANOVAs were condition (four levels, no-scent control, orange, seawater, and peppermint), location (three levels), and gender (two levels). Age was used as covariate. Although gender and age were not of direct interest for the study, they were included to correct for any possible influences of these variables.

To investigate whether scents affected the dependent variables compared to the unscented control condition, we tested whether the observations in the three scented experimental conditions differed significantly from those in the two unscented control conditions in two-tailed $t$ tests for independent samples. Differences between the three experimental conditions (orange, seawater, or peppermint) were investigated by two-tailed post hoc $t$ tests with Bonferroni adjustment.

\section{Results}

\section{Observational Measures}

The repeated measures ANOVAs for the sales data yielded no significant effect for condition ( $p>0.20$ for all analyses, $0.10<\eta^{2}<0.44$ ); Fig. 3 shows the mean values for total revenue. The ANOVA for the number of visitors also showed no significant effect of condition $[F(1.2,2.4)=1.8$, $p>0.20, \eta^{2}=0.47$; see Fig. 3].

Both dancing activity $[F(1.9,3.7)=22.2, p<0.01$, and $\left.\eta^{2}=0.92\right]$ and temperature $[F(1.2,2.4)=20.8, p<0.05$, and $\left.\eta^{2}=0.91\right]$ showed significant differences between conditions (see Fig. 4). The three scented conditions showed more dancing activity than the unscented control conditions [two-tailed $t(26)=-6.0, p<0.001]$. Dancing activity did not differ between the three experimental conditions [all $p>0.20$ ].

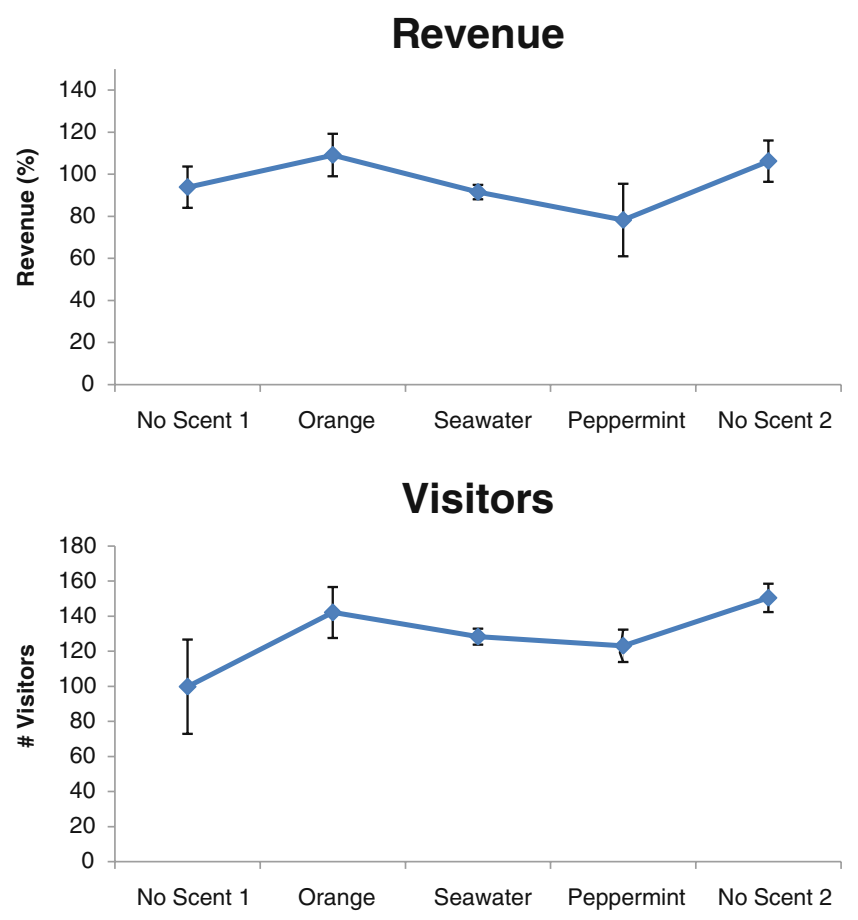

Fig. 3 Effect of environmental fragrancing on total revenue and number of visitors (mean $\pm \mathrm{SE}$ )

Similarly, in the three scented conditions, the temperature inside the club tended to be higher than in the unscented control condition [two-tailed $t(26)=-7.2, p<0.001]$. Differences between the three experimental conditions failed to

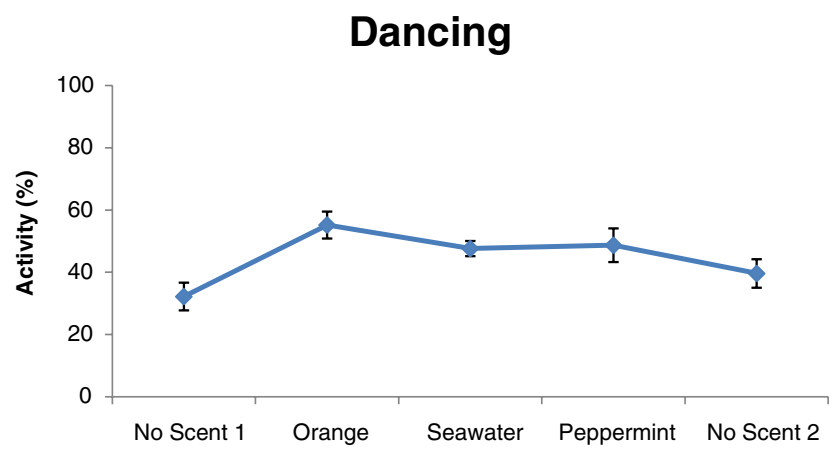

Temperature

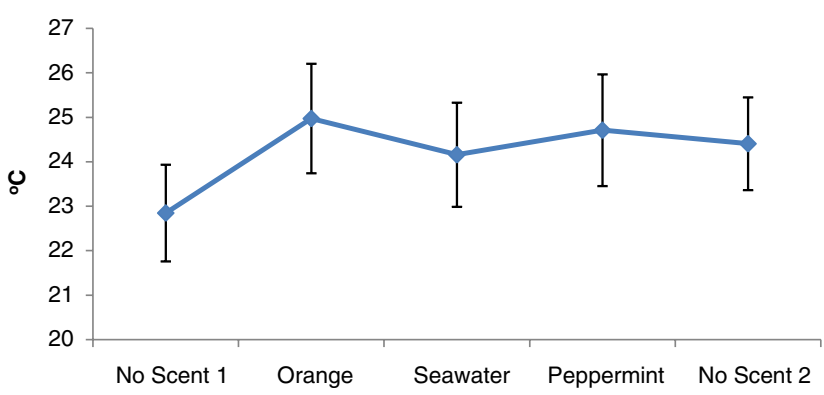

Fig. 4 Effect of environmental fragrancing on dancing activity and temperature inside the club $($ mean $\pm \mathrm{SE})$ 
reach significance, although the temperature in the clubs with orange scent showed a tendency to be higher than in the clubs with seawater scent $(p=0.07)$.

\section{Self-Report Measures}

In the description of the analyses of the self-report measures, we mainly focus on the scent main effect and the scent $\times$ location interaction because these are our main variables of interest. The ANOVA for the evaluation of the evening showed a main effect of scent $[F(3,813)=4.8$, $p<0.01$, and $\left.\eta^{2}=0.02\right]$ and a scent $\times$ location interaction $\left[F(6,813)=4.0, p<0.001\right.$, and $\left.\eta^{2}=0.03\right]$. Evaluations of the evening were more positive in the scented conditions than in the control conditions [two-tailed $t(629)=-3.9, p<0.001$ ] (see Fig. 5).

The ANOVA for the evaluation of the music showed a main effect of scent $\left[F(3,813)=2.8, p<0.05\right.$, and $\left.\eta^{2}=0.01\right]$ and a scent $\times$ location interaction $[F(6,813)=3.7, p<0.001$, and $\left.\eta^{2}=0.03\right]$. In addition, the effect of the age covariate was significant $\left[F(1,813)=4.7, p<0.05\right.$, and $\left.\eta^{2}=0.01\right]$. Evaluations of the music tended to be more positive for the scented than in the unscented conditions [two-tailed $t(661)=-2.6, p<0.01]$.

The ANOVA for the evaluation of the club showed no main effect of scent $\left[F(3,813)=1.8, p>0.10\right.$, and $\left.\eta^{2}=0.01\right]$, but only a scent $\times$ location interaction $[F(6,813)=4.5$,
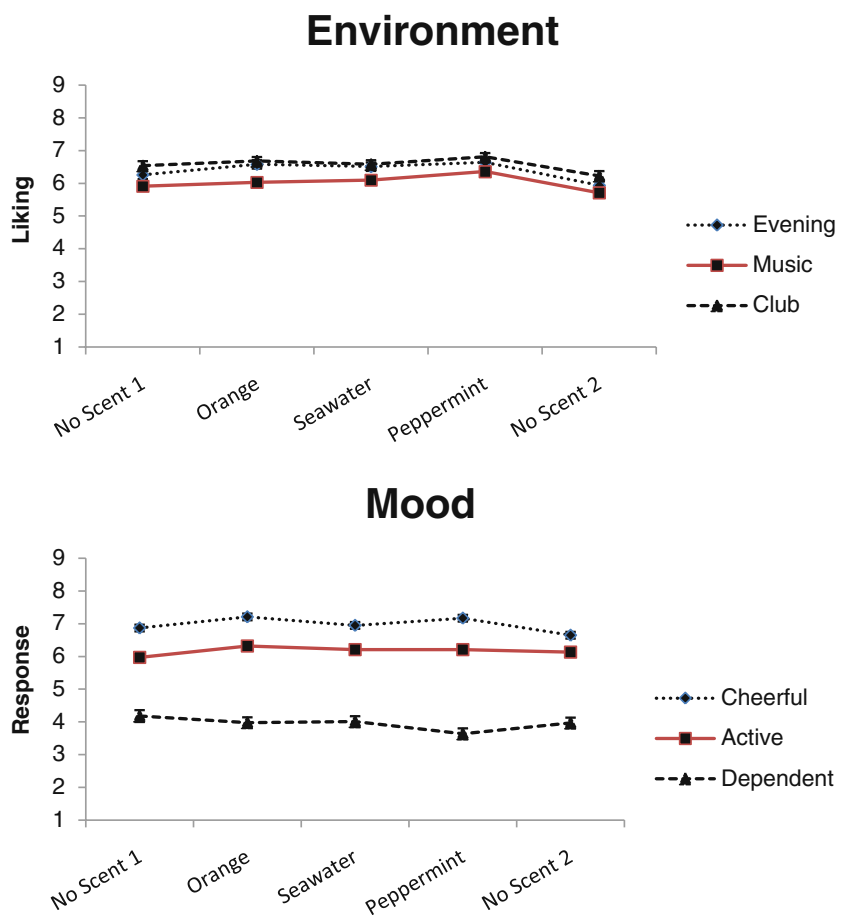

Fig. 5 Effect of environmental fragrancing on evaluations of the environment and on personal mood dimensions (mean $\pm \mathrm{SE}$ ) $p<0.001$, and $\left.\eta^{2}=0.03\right]$ and an effect of the age covariate $\left[F(1,813)=21.1, p<0.001\right.$, and $\left.\eta^{2}=0.03\right]$. Nonetheless, on average, the evaluations of the club were more positive in the scented conditions than in the control conditions [two-tailed $t(633)=-2.5, p<0.05]$.

For the first mood variable, sad-cheerful, the ANOVA showed a significant main effect of scent $[F(3,810)=4.1$, $p<0.01$, and $\left.\eta^{2}=0.02\right]$, but no scent $\times$ location interaction $\left[F(6,810)=1.8, p>0.10\right.$, and $\left.\eta^{2}=0.01\right]$. Visitors reported to be more cheerful in the scented conditions than in the control conditions [two-tailed $t(629)=-3.2, p<0.001$ ] (see Fig. 5). For quiet-active and independent-dependent, the ANOVAs showed no scent main effects $(p>0.20)$ nor scent $\times$ location interactions $(p>0.05)$, and the $t$ test did not detect a significant difference between scented and control conditions $(p>0.10)$.

Differences between the three fragrances did not reach significance for any of the self-report measures investigated $(p>0.10)$.

\section{Mediation Analysis}

Overall, the results suggest that the scents improved evaluations of the evening, the music, and the club, and also enhanced the cheerfulness of the visitors. Correlations among these dependent variables were all substantial $(0.45$ $<r<0.65, p<0.001$, and $N>844$ ). This could imply that the scent effect on some dependent variable may be mediated by the scent effect on another variable. For instance, scents may directly affect the mood of the visitors, and due to the improvement in mood, the visitors may evaluate the evening more favorably. In order to investigate this relationship, whether visitor mood acts as a mediator of the effect of scents on the evaluation of the evening was examined via the approach detailed below suggested by Baron and Kenny (1986). Because the evaluation of the evening was the most general type of evaluation and showed the largest effect of scent in the ANOVAs, it was the only dependent variable investigated in the analysis of mediation.

Although pleasure, arousal, and dominance are supposed to reflect independent dimensions of affective experience (Mehrabian and Russell 1974), in the current study, responses on the sad-cheerful scale were highly correlated with those on the quiet-active scale (Pearson $r=0.54, p<0.001$, and $N=828$ ). In addition, statistically significant correlations were found between sad-cheerful and independent-dependent ( $r=-0.15, p<0.001$, and $N=823$ ), and between quiet-active and independent-dependent $(r=-0.09, p<0.01$, and $N=822)$, but in these cases, the correlation coefficients were much lower. In order to avoid multicollinearity in the mediation analyses, only the responses on the sad-cheerful scale were used as mediation variable, since this is the only variable for which significant scent effects were found. 
According to Baron and Kenny (1986), mediation can be assessed by performing the following regression analyses: (1) regressing the mediator (mood) on the independent variable (scent); (2) regressing the dependent variable (evaluation evening) on the independent variable (scent); and (3) regressing the dependent variable on both the mediator and the independent variable. In all regression analyses, the cheerful variable and the evaluation variable were continuous variables (responses varying from 1 to 9), while the scent effect manipulation was a dummy variable $(1=$ scent versus $0=$ no scent). Two additional dummy variables were included in all regression equations to code for any between-location differences.

Analyses 2 and 3 in Table 2 indicate that the effect of scent on the evaluation of the evening decreased when the visitor's degree of cheerfulness was entered in the equation. This suggests that the effect of scents is at least partly mediated by the mood of the visitors. After the cheerfulness of the visitor has entered the equation, the regression coefficients for the scent effect remain positive. However, this effect is only statistically significant in the analysis performed for seawater scent and in the overall analysis of the three scents. The latter results suggest that the scent may have a small effect on the evaluation of the evening that is independent of the mood improvement.

\section{Discussion}

\section{General Findings}

The present results suggest that environmental fragrancing may provide a solution to the unpleasant smells in nightclubs that sometimes have appeared since smoking was prohibited. The pleasant scents in the present study increased dancing activity, and they improved the evaluation of the evening, the evaluation of the music, and the mood (i.e,. cheerfulness) of the visitors. The study thereby roughly confirms positive effects previously found in retail stores (e.g., Spangenberg et al. 1996) and expands these to the nightlife experience.
As regards the type of scent, differences between the three scents were generally not statistically significant. This outcome contradicts our hypothesis that a stimulating smell (peppermint) would enhance dancing activity, whereas a relaxing smell (orange) would attenuate dancing activity. Instead, we found that all scents enhanced dancing activity. The increase in dancing activity seems to coincide with an increase in temperature in the club. Possibly, these two variables are correlated, in the sense that more dancing activity increases the visitors' heat production and, thereby, increases the temperature in the nightclub. Changes in outside temperature are unlikely to account for our findings because it went down steadily by $5{ }^{\circ} \mathrm{C}$ over the five testing weeks.

In line with traditional models of environmental psychology (e.g., Mehrabian and Russell 1974), our mediation analysis suggests that the effects of scents on the evaluation of the evening are at least partly mediated by the visitors' mood. Please note that this analysis cannot be used to determine the causal order in which effects occur. Chebat and Michon (2003) recently suggested that the change in evaluation of the environment may actually precede the change in people's mood. These authors used structural equation modeling to provide support for a cognition-affect model in which scent affected the perception of the environment and product quality, which in their turn affected mood and consumer spending. Alternatively, the effects might be interpreted as stemming from a halo effect (Thorndike 1920). A halo effect implies that one positive stimulus feature may induce favorable opinions on other - seemingly unrelated - characteristics. As a result, responses on various positive scales may become correlated. Hence, a halo explanation suggests that all changes in evaluation of the nightclub environment and visitors' mood occur simultaneously, not in any particular order. Unfortunately, the current data do not allow us to distinguish between these alternative explanations.

Spangenberg et al. (1996) found strong effects of pleasant ambient scents on evaluations of store environment, but weaker effects on product judgments. This difference may occur because an ambient odor is diagnostic

Table 2 Mediation analysis for evaluation of the evening, showing the standardized beta weights in regression analysis

\begin{tabular}{lllllll}
\hline Step & Dependent variable & Independent variables & Orange & Seawater & Peppermint & All three scents \\
\hline 1. & Cheerful & Scent & $0.14^{*}$ & 0.06 & $0.12^{* *}$ & $0.11^{*}$ \\
2. & Evaluation evening & Scent & $0.13^{* *}$ & $0.11^{* *}$ & $0.15^{*}$ & $0.14^{*}$ \\
3. & Evaluation evening & Scent & 0.05 & $0.07 * *$ & 0.07 & $0.06^{* * *}$ \\
& & Cheerful & $0.58^{*}$ & $0.66^{*}$ & $0.63^{*}$ & $0.63^{*}$ \\
\hline
\end{tabular}

Analyses were done for the individual scents and for the ensemble of three scents, comparing scented with unscented conditions

${ }^{*} p<0.001,{ }^{* *} p<0.01, * * * p<0.05$ 
for the store atmosphere, but not for a particular product if that product does not emit the scent. Olfactory information needs to compete with other information for the attention of the observer, and since it is in many cases rather ambiguous, it often loses this battle. Therefore, the effect of an ambient scent on the evaluation of individual products in stores may be rather small. Nonetheless, Bosmans's (2006) study suggests that even an incongruent, pleasant scent can have a positive effect on product evaluations, although the size of this effect depends on how salient the scent is.

However, the case may be different for nightclubs or restaurants, where products are consumed on the spot. Some scents may have an adverse or beneficial effect on the consumption of specific beverages, depending on whether their combination of sensory properties clashes or not. For instance, the authors observed that peppermint scent and beer are not a good combination. If certain combinations are regarded unpleasant, the scents may decrease sales for specific products. On the other hand, they can also act as cues that increase sales for specific drinks (e.g., orange scent for orange juice or orange-mix drinks).

\section{Methodological Limitations}

In the present study, a 5-week time frame was used. This turned out to be sufficient for obtaining scent-induced differences on several questionnaire items, but not to affect revenue. Whereas responses on 849 questionnaires (48-60 per night per club) were obtained, only 15 observations for revenue (one per night per club) were registered. Possibly, more observations could lead to more significant differences between scents.

In addition, some of the dependent measures might be improved in subsequent studies. When it was very busy during club nights, we noticed that bar personnel was sometimes unable to serve all visitors in time. If a more crowded bar implies that visitors have to wait longer for their drinks, revenue does not increase linearly with popularity of the bar. Therefore, future studies should take bar capacity into account when assessing beverage sales. Furthermore, we measured the activity of the visitors in a subjective manner. In order to obtain a more objective measure in future research, the dance floor might be filmed using a camera with movement sensor. In addition, an electronic counting system could be placed at the door and a camera could be installed above the dance floor in order to determine the total number of visitors.

Although visitor mood was assessed via SAM scales on three purportedly independent dimensions, in the present investigation, they were highly correlated. However, these correlations do not necessarily invalidate the PAD model or the SAM scales, but may be induced by the environments used as stimuli. Several previous empirical studies have found substantial intercorrelations between the dimensions (e.g., Osgood et al. 1957). According to Mehrabian and Russell (1974), arousal amplifies approach behavior in pleasant environments and avoidance behavior in unpleasant environments. Because in the present study arousal is correlated positively with pleasantness, increases in arousal and pleasantness are both likely to correlate with increases in approach behaviors, such as duration of stay, interaction with other visitors, intention to visit the club again, and so on.

\section{Practical Implications}

Although clubs and bars look for ways to differentiate themselves from their competitors, they are also likely to encounter barriers in adopting new technologies and innovative experience concepts (e.g., Fuglsang and Sorensen 2009). Given that visitors gave a better evaluation for the clubs, felt more cheerful, and showed more dancing activity when scents were diffused, environmental fragrancing may be expected to have a positive effect on visitor return rate and future revenue for clubs. However, more empirical testing is needed to show whether these effects will occur and how large they are.

In a bar or nightclub environment, the music and the lights have always been important factors to create the desired atmosphere. By combining the lights and sounds with ambient scent, a full multisensory experience can be created, stimulating all senses at the same time. It is important that when scents are added, they should be in balance with lights and music (e.g., Schifferstein and Desmet 2008). For example, high arousal music should preferably be combined with high arousal scents (Mattila and Wirtz 2001). It may be worthwhile to develop scents that are especially designed for nightclubs and that can be dispersed throughout the night. Such a scent could become a signature scent for a specific club (e.g., Goldkuhl and Styven 2007) and may become part of that club's brand identity. Alternatively, it may be possible to develop a set of scents that enhances the different experiences that occur during the night, depending on the crowding, the type of music, the degree of fatigue or intoxication of the customers, and the wishes of the club owner (e.g., to relax or activate the crowd, or to stimulate the last customers to go home). At present, some innovative nightclubs are already inviting aroma jockeys, who generate multiple smells over the night that are congruent 
with the music that is played at that specific moment (Odo7 2010). Whether these smells are really effective in enhancing the nightlife experience remains a topic for further investigation.

Acknowledgments The authors are indebted to RetroScent (Rotterdam) for providing the fragrances and the diffusing systems and to the management and personnel of Lorre (Delft), Heerenplein (Utrecht), and City Hall (Leiden) for giving us the opportunity to test the fragrance systems.

Open Access This article is distributed under the terms of the Creative Commons Attribution Noncommercial License which permits any noncommercial use, distribution, and reproduction in any medium, provided the original author(s) and source are credited.

\section{References}

Baron RA (1990) Environmentally induced positive affect: its impact on self-efficacy, task performance, negotiation, and conflict. J Appl Soc Psychol 20:368-384

Baron RA (1997) The sweet smell of...helping: effects of pleasant ambient fragrance on prosocial behavior in shopping malls. Pers Soc Psychol Bull 23:498-503

Baron RM, Kenny DA (1986) The moderator-mediator variable distinction in social psychological research: conceptual, strategic, and statistical considerations. J Pers Soc Psychol 51:11731182

Baron RA, Thomley J (1994) A whiff of reality - positive affect as a potential mediator of the effects of pleasant fragrances on task performance and helping. Environ Behav 26:766-784

Bone PF, Ellen PS (1999) Scents in the marketplace: explaining a fraction of olfaction. J Retail 75(2):243-262

Bosmans A (2006) Scents and sensibility: when do (in)congruent ambient scents influence product evaluations. J Mark 70:32-43

Bradley MM, Lang PJ (1994) Measuring emotion: the self-assessment manikin and the semantic differential. J Behav Ther Exp Psychiatry 25:49-59

Cann A, Ross DA (1989) Olfactory stimuli as context cues in human memory. Am J Psychol 102(1):91-102

Chebat JC, Michon R (2003) Impact of ambient odors on mall shoppers' emotions, cognition, and spending - a test of competitive causal theories. J Bus Res 56:529-539

Chebat JC, Morrin M, Chebat DR (2009) Does age attenuate the impact of pleasant ambient scent on consumer response? Environ Behav 41:258-267

Chrea C, Grandjean D, Delplanque S, Cayeux I, Le Calvé B, Aymard L, Velazco MI, Sander D, Scherer KR (2009) Mapping the semantic space for the subjective experience of emotional responses to odors. Chem Senses 34:49-62

Ehrlichman H, Bastone LM (1992) Olfaction and emotion. In: Serby MJ, Chobor L (eds) Science of olfaction. Springer, New York, pp $427-451$

Ehrlichman H, Halpern JN (1988) Affect and memory: effects of pleasant and unpleasant odors on retrieval of happy and unhappy memories. J Pers Soc Psychol 55(5):769-779

Engen T (1982) The perception of odors. Academic, New York

Fiore AM, Yah X, Yoh E (2000) Effects of a product display and environmental fragrancing on approach responses and pleasurable experiences. Psychol Mark 17:27-54
Fragrance Foundation UK (2007) Women's fragrances. UK Market Intelligence Report

Fuglsang L, Sorensen F (2009) The law of Jante as a cultural barrier for entrepreneurship and innovation in the experience economy. Paper presented at the 9th EURAM Conference on Renaissance and Renewal in Management Studies, Liverpool, UK

Goldkuhl L, Styven M (2007) Sensing the scent of service success. Eur J Mark 41:1297-1305

Gulas CS, Bloch PH (1995) Right under our noses: ambient scent and consumer responses. J Bus Psychol 10(1):87-98

Ho C, Spence C (2005) Olfactory facilitation of dual-task performance. Neurosci Lett 389:35-40

Knasko SC (1989) Ambient odor and shopping behavior. Chem Senses 14:718

Knasko SC (1995) Pleasant odors and congruency: effects on approach behavior. Chem Senses 20:479-487

Lang PJ (1985) The cognitive psychophysiology of emotion: anxiety and the anxiety disorders. Erlbaum, Hillsdale

Leenders MAAM, Smidts A, Langeveld M (1999) Effects of ambient scent in supermarkets: A field experiment. Paper presented at the 28th EMAC conference, Berlin, Germany

Lehrner J, Eckersberger C, Walla P, Potsch G, Deecke L (2000) Ambient odor of orange in a dental office reduces anxiety and improves mood in female patients. Physiol Behav 71:8386

Lehrner J, Marwinski G, Lehr S, Johren P, Deecke L (2005) Ambient odors of orange and lavender reduce anxiety and improve mood in a dental office. Physiol Behav 86:92-95

Mattila AS, Wirtz J (2001) Congruency of scent and music as a driver of in-store evaluations and behavior. J Retail 77:273-289

Mehrabian A, Russell JA (1974) An approach to environmental psychology. MIT, Cambridge

Morrin M, Ratneshwar S (2000) The impact of ambient scent on evaluation, attention, and memory for familiar and unfamiliar brands. J Bus Res 49:157-165

Moss M, Cook J, Wesnes K, Duckett P (2003) Aromas of rosemary and lavender essential oils differentially affect cognition and mood in healthy adults. Int J Neurosci 113:15-38

Moss M, Howarth R, Wilkinson L, Wesnes K (2006) Expectancy and the aroma of Roman chamomile influence mood and cognition in healthy volunteers. Int J Aromather 16:63-73

Moss M, Hewitt S, Moss L, Wesnes K (2008) Modulation of cognitive performance and mood by aromas of peppermint and ylang-ylang. Int J Neurosci 118:59-77

Nixdorf RR, Teerling A, Köster EP (1992) The effect of olfactory stimuli on the time spent by customers in textile-departmentstores. Paper presented at the 14th AChems conference, Sarasota, USA

Odo7 (2010) Fragrant heaven. Available at http://odo7.com/. Accessed 22 April 2010

Osgood CE, Suci GJ, Tannenbaum PH (1957) The measurement of meaning. University of Illinois Press, Urbana

Schifferstein HNJ, Blok ST (2002) The signal function of thematically (in)congruent ambient scents in a retail environment. Chem Senses 27:539-549

Schifferstein HNJ, Desmet PMA (2008) Tools facilitating multisensory product design. Des J 11(2):137-158

Schifferstein HNJ, Tanudjaja I (2004) Visualising fragrances through colours: the mediating role of emotions. Perception 33:12491266

Schifferstein HNJ, Verlegh PWJ (1996) The role of congruency and pleasantness in odor-induced taste enhancement. Acta Psychol 94:87-105 
Spangenberg ER, Crowley AE, Henderson PW (1996) Improving the store environment: do olfactory cues affect evaluations and behaviors? J Mark 60:67-80 (April)

Spangenberg ER, Grohmann B, Sprott DE (2005) It's beginning to smell (and sound) a lot like Christmas: the interactive effects of ambient scent and music in a retail setting. J Bus Res 58:15831589

Spangenberg ER, Sprott DE, Grohmann B, Tracy DL (2006) Gendercongruent ambient scent influences on approach and avoidance behaviors in a retail store. J Bus Res 59:1281-1287

Stevens JP (2002) Applied multivariate statistics for the social sciences, 4th edn. Erlbaum, Mahwah

Thorndike EL (1920) A constant error in psychological ratings. J Appl Psychol 4:25-29
Warm JS, Dember WN, Parasuraman R (1991) Effects of olfactory stimulation on performance and stress in a visual sustained attention task. J Soc Cosmet Chem 42:199-210

Warren C, Warrenburg S (1993) Mood benefits of fragrance. Perfum Flavor 18:9-16 (March)

Warren CB et al (1987) Method of causing the reduction of physiological and/or subjective reactivity to stress in human beings subjected to stress conditions. US patent no. 4,671,959

Warrenburg S (2002) Measurement of emotion in olfactory research. In: Given P, Paredes D (eds) Chemistry of taste: mechanisms, behaviors, and mimics. American Chemical Society, Washington, pp 243-260

Zemke DM, Shoemaker S (2007) Scent across a crowded room: exploring the effect of ambient scent on social interactions. Int $\mathrm{J}$ Hosp Manag 26:927-940 